\title{
Komunikasi Interpersonal Siswa Pengguna Internet dan Implikasinya terhadap Layanan Bimbingan dan Konseling
}

Winda Marnita, Riska Ahmad \& Azrul Said

Universitas Negeri Padang

\begin{abstract}
Interpersonal communication through the internet is now becoming a trend among the public, especially students. Online communication is of interest by students because it is cheap, easy and fast. The Internet as a communication medium between the interpersonal students with parents, teachers and fellow internet users. The use of the internet as a medium of interpersonal communication understood the students well. Aspects that should be understood in communicating interpersonal are students use of the internet, the purpose of the use of the internet, openness, attention, empathy, equality. This research is descriptive research, the population in this study are students of SMP Negeri Padang 25 that become the subject of research is as much as 69 students, data collected by using question form. This study reveals students' interpersonal communication through the internet and the implications for guidance and counselling services. Because most of students have yet to understand and implement the aspects of the accommodation.
\end{abstract}

Keyword: interpersonal communication, use of internet

Copyright $\odot 2014$ IICE - Multikarya Kons (Padang - Indonesia) dan IKI - Ikatan Konselor Indonesia - All Rights Reserved

Indonesian Institute for Counseling and Education (IICE) Multikarya Kons

\section{PENDAHULUAN}

Perkembangan ilmu pengetahuan dan teknologi yang pesat saat ini memberikan kemudahan bagi kehidupan manusia. Hubungan antar manusia di belahan bumi menjadi terasa dekat, dengan kemajuan teknologi khususnya di bidang informatika dan komunikasi membantu manusia dapat berkomunikasi dengan mudah walaupun berada di tempat yang saling berjauhan. Manusia memanfaatkan teknologi yang canggih untuk dapat saling berinteraksi dengan mudah dan cepat.

Di dalam kehidupan manusia memerlukan komunikasi agar dapat bertukar informasi kepada manusia lainnya. Sebagaimana yang dijelaskan oleh Theodorson (dalam Burhan Bungin 2009: 30)

Memberi batasan lingkup communication berupa penyebaran informasi, ide-ide, sikap-sikap, emosi dari seorang atau kelompok kepada yang lain (atau lain-lainnya) terutama melalui simbol-simbol.

Majunya teknologi informasi ditandai dengan hadirnya internet yang memiliki beragam fitur-fitur yang canggih sebagai pendukungnya. Seperti yang dikemukakan oleh Severin dan Tankard (2001: 6) "internet pada dasarnya sebuah jaringan antar-komputer yang saling berkaitan. Jaringan ini tersedia terus menerus sabagai pesan elektronik, termasuk email, transmisi file, komunikasi dua arah antar individu atau komputer".

Menurut Mortiner \& Larson, Seattler (dalam Santrock 2007: 218) mengatakan

Sekarang ini, terjadi perubahan besar di mana penggunaan komputer dan internet oleh remaja meningkat pesat melebihi kecepatan dalam revolusi teknologi. Dapat disimpulkan bahwa remaja merupakan pengguna internet terbesar saat ini. 
Menurut Mc Kenna dan Bargh, Young (dalam Michaelyani : 2010) menyatakan:

Internet dapat menjadi suatu teknologi sosial yang besar untuk membantu orang untuk berhubungan dengan orang lain dan untuk memperluas cakrawala sosial mereka. Pada saat yang sama, Internet bisa menjadi suatu teknologi sosial mengisolasi jika orang menggunakannya untuk menghindari kontak dengan orang-orang di sekitar mereka dan melarikan diri dari dunia nyata.

Sejalan dengan hal di atas Berdasarkan penelitian Young dalam Michaelyani (2010) menyatakan:

Remaja menghabiskan lebih banyak waktu online, kurang keinginan mereka untuk melihat dan berbicara dengan anggota keluarga langsung mereka. Beberapa orang mungkin berpendapat bahwa mungkin sebaliknya remaja kurang memiliki keinginan untuk berinteraksi dengan keluarga mereka, semakin mereka online.

Fenomena yang terjadi hampir semua siswa memiliki facebook atau twitter serta situs perteman sosial lainnya. Situs-situs ini sangat diminati oleh para karena tidak hanya bisa diakses melalui komputer, laptop, handphone dan tablet pc. Hampir semua siswa memiliki akun atau menjadi anggota dari situs pertemanan sosial ini. Namun, siswa lebih senang mengemukakan mengenai dirinya di internet khususnya media sosial daripada menceritakan kepada orang tua, guru, atau teman sebayanya.

Komunikasi Interpersonal menurut Tan (dalam Alo Liliweri 1997: 66) "komunikasi antarpribadi adalah komunikasi tatap muka antara dua orang". Seiring dengan perkembangan teknologi komunikasi interpersonal berkembang dengan memanfaatkan internet sebagai medianya. Komunikasi interpersonal bermedia internet sangat disenangi oleh sebagian besar siswa saat ini.

Berdasarkan pengamatan yang dilakukan terhadap beberapa remaja yang duduk di kelas VII dan kelas VIII SMP Negeri 25 Padang pada bulan Maret sampai Juni 2012. Siswa menghabiskan waktu di warnet dan di depan komputer untuk online. Siswa menjadi anggota cyber community dimana mereka berinteraksi dengan komunitas dunia maya lainnya.

Berdasarkan wawancara dengan salah seorang wali kelas VII.1 dan VII.4 di SMP Negeri 25 Padang mengatakan bahwa sebagian besar siswa yang menghabiskan waktunya untuk ke warnet hanya untuk membuka beberapa situs jejaring sosial. Ketika siswa disuruh mencari materi di internet siswa lebih tertarik membuka situs facebook untuk online. Siswa mengenal dan menjadi anggota jejarig sosial.

Selain itu berdasarkan wawancara dengan beberapa orang siswa mereka mengatakan bahwa senang berkomunikasi melalui internet yang lebih dikenal dengan chatting dan siswa-siswa ini juga sering menuliskan pesan melalui jejaring sosial seperti facebook, twitter dan lainya.

Berdasarkan penelitian sebelumnya yang dilakukan oleh Anne Ratnasari (2005: 117-118) mengenai "Pengaruh Komunikasi Interpersonal Bermedia Internet Terhadap Persahabatan Di Dunia Maya" menyimpulkan bahwa komunikasi interpersonal bermedia internet sebagai sarana komunikasi yang memiliki berbagai kelebihan sehingga mengimbangi komunikasi secara tatap-muka.

\section{METODOLOGI PENELITIAN}

Penelitian ini menggunakan metode kuantitatif dengan pendekatan analisis deskriptif. Populasi penelitian ini adalah siswa SMP Negeri 25 Padang di SMP Negeri Kota Padang, sedangkan subjek dalam penelitian ini berjumlah 69 orang. Instrumen yang digunakan untuk mengumpulkan data dalam penelitian ini adalah angket. Jenis angket yang digunakan dalam penelitian ini adalah angket tertutup dengan menggunakan skala bebas dengan empat alternatif pilihan jawaban yaitu "selalu", "sering", "kadang-kadang" dan "tidak pernah". Data yang diperoleh dianalisis dengan menggunakan teknik persentase yang dikemukakan oleh A Muri Yusuf (1997: 349)

$$
\mathrm{P}=\frac{f}{n} \times 100
$$

Keterangan :

$P=$ Persentase jawaban

$\mathrm{f}=$ Frekuensi jawaban

$\mathrm{n}=$ Jumlah keseluruhan responden 


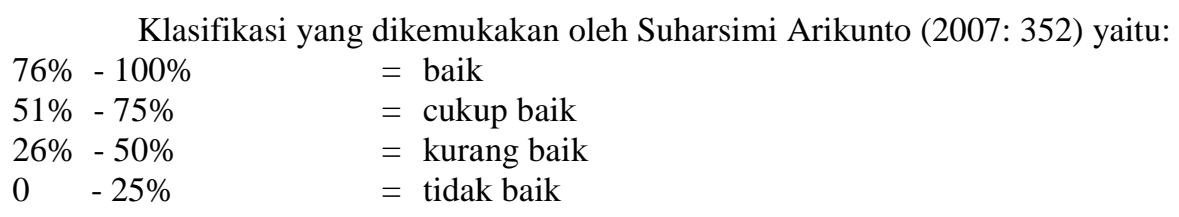

HASIL

Berdasarkan hasil pengolahan data, maka hasil penelitian ini dapat digambarkan sebagai berikut:

Tabel 1. Rekapitulasi Komunikasi Interpersonal Siswa SMP Negeri 25 Padang

\begin{tabular}{|c|l|c|}
\hline No. & $\begin{array}{c}\text { Komunikasi } \\
\text { Interpersonal Siswa } \\
\text { Pengguna Internet }\end{array}$ & $\begin{array}{c}\text { Persentase } \\
\mathbf{\%}\end{array}$ \\
\hline 1 & $\begin{array}{l}\text { Penggunaan Internet } \\
\text { dalam berkomunikasi } \\
\text { Interpersonal }\end{array}$ & 24.93 \\
\hline
\end{tabular}

Berdasarkan tabel di atas dapat dilihat bahwa keseluruhan penggunaan internet oleh siswa untuk berkomunikasi interpersonal dalam hal berinteraksi dengan pengguna lain, memberikan tanggapan, menyampaikan pesan, memberikan informasi, dan menerima informasi yaitu $24.93 \%$ siswa yang selalu menggunakan internet untuk berkomunikasi interpersonal.

\section{Tabel 2. Rekapitulasi Komunikasi Interpersonal Siswa SMP Negeri 25 Padang}

\begin{tabular}{|c|l|c|c|}
\hline No. & $\begin{array}{c}\text { Komunikasi } \\
\text { Interpersonal } \\
\text { Siswa Pengguna } \\
\text { Internet }\end{array}$ & $\begin{array}{c}\text { Persentase } \\
\%\end{array}$ & Kategori \\
\hline 1 & $\begin{array}{l}\text { Keterbukaan } \\
\text { dalam } \\
\text { berkomunikasi }\end{array}$ & 19.65 & Tidak Baik \\
\hline 2 & $\begin{array}{l}\text { Perhatian dalam } \\
\text { berkomunikasi }\end{array}$ & 9.21 & Tidak Baik \\
\hline 3 & $\begin{array}{l}\text { Empati dalam } \\
\text { berkomunikasi }\end{array}$ & 21.44 & Tidak Baik \\
\hline 4 & $\begin{array}{l}\text { Kesetaraan } \\
\text { dalam } \\
\text { berkomunikasi }\end{array}$ & 19.65 & Tidak Baik \\
\hline
\end{tabular}

Berdasarkan tabel di atas dapat dilihat bahwa 19.65\% siswa memiliki keterbukaan dalam komunikasi interpersonal melalui internet, sehingga dapat disimpulkan keterbukaan siswa dalam komunikasi interpersonal tergolong tidak baik, $9.21 \%$ siswa memberikan perhatian dalam komunikasi interpersonal melalui internet, sehingga dapat disimpulkan perhatian siswa tergolong tidak baik, 21.44\% memiliki empati dalam komunikasi interpersonal melalui internet, sehingga dapat disimpulkan empati siswa dalam komunikasi interpersonal melalui internet tergolong tidak baik, rata-rata skor jawaban siswa memilih $19.65 \%$ memperhatikan kesetaraan dalam komunikasi interpersonal melalui internet, sehingga dapat disimpulkan kesetaraan siswa dalam komunikasi interpersonal melalui internet tergolong kurang baik. 


\section{PEMBAHASAN}

\section{Komunikasi Interpersonal Siswa Pengguna Internet}

Devito (2011: 22) mengemukakan "komunikasi interpersonal yaitu komunikasi antara dua individu." Sejalan dengan itu menurut Hafied Canggara (2008: 32) komunikasi interpersonal merupakan proses komunikasi yang berlangsung antara dua orang atau lebih secara tatap muka. Seperti yang dinyatakan Pace dalam Hafied Canggara (2008: 32) bahwa "interpersonal communication is communication involving two more people in face to face setting."

Menurut Levy (dalam Severin dan Tankard 2005: 6) internet sebagai "saluran komunikasi yang tidak terbatas, pembangunan komunikasi, iklan elektronik dan interaksi yang sangat kompleks yang mengaburkan batas antara penyedia dan konsumen."

The Graphic, Visualization \& Usability Center, the Georgia Institute of Technology (dalam Surya: 2002) menggolongkan pengguna Situs Jejaring Sosial menjadi tiga kategori dengan berdasarkan intensitas Situs Jejaring Sosial yang digunakan:

1) Heavy users (lebih dari 40 jam per bulan) lebih 1.5 jam per hari

2) Medium users (antara 10 sampai 40 jam per bulan) antara 1.5 jam per hari

3) Light users (kurang dari 10 jam per bulan) kurang dari 1.5 jam per hari

Horrigan (dalam Astutik : 2002) menggolongkan aktivitas - aktivitas Situs Jejaring Sosial yang dilakukan para pengguna Situs Jejaring Sosial menjadi empat kelompok kepentingan penggunaan Situs Jejaring Sosial, yaitu:

1. Berkirim pesan melalui E-mail

2. Aktivitas kesenangan (Fun activities) yaitu aktivitas yang sifatnya untuk kesenangan atau hiburan.

3. Kepentingan informasi

(Information utility) yaitu aktivitas internet untuk mencari informasi, seperti: informasi produk, informasi travel, cuaca, informasi keuangan, informasi pekerjaan, atau informasi tentang politik.

4. Transaksi (Transaction), yaitu aktivitas transaksi (jual beli) melalui Situs Jejaring Sosial, seperti: membeli sesuatu, memesan tiket perjalanan.

Menurut Rogers (dalam Hafied Canggara 2008: 33) "proses komunikasi yang menggunakan alat elektronik seperti itu, masih dapat dikategorikan sebagai proses komunikasi massa atau komunikasi antar pribadi." "Machine-assited interpersonal communication is the telephone, it does not fit into either category of mass media or interpersonal channel because it is neither face-to-face nor one-to-many."

\section{Adapun fokus dari penelitian ini adalah sebagai berikut:}

\section{Penggunaan Internet}

Berdasarkan hasil penelitian yang dilakukan, diketahui bahwa bahwa 34 orang siswa atau $49.28 \%$ siswa yang menggunakan internet untuk berkomunikasi interpersonal dalam hal berinteraksi dengan pengguna lain, memberikan tanggapan, menyampaikan pendapat, mencari informasi, dan menerima informasi.

Sejalan dengan hal itu menurut Laque (dalam Ardianto, dkk 2007: ) membedakan internet (dan jaringan global lainnya) dari teknologi komunikasi traditional adalah tingkat interaksi dan kecepatan yang dinikmati pengguna untuk menyiarkan pesannya. Tak ada media yang memberi setiap penggunanya kemampuan untuk berkomunikasi secara seketika dengan ribuan orang.

Santrock (2007: 218) menyatakan bahwa:

Internet merupakan sarana inti dari komputer untuk berkomunikasi. Sistem internet dapat meliputi seluruh dunia dan melibatkan ribuan koneksi jaringan komputer, memberikan sejumlah informasi yang luar biasa banyaknya yang dapat ditelusuri oleh remaja.

Selain itu menurut Werner J.Severin dan James W. Tankard Jr, (2005: 8) tiga fitur utama Internet, yaitu email (surat elektronik), News Group and Mailing List, serta World Wide Web.

Selain itu Ardianto, dkk (2007: 151) mengemukakan “Internet dihuni oleh jutaan orang nonteknik yang menggunakan setiap hari untuk berkomunikasi dan mencari informasi”. 


\section{Keterbukaan dalam Komunikasi melalui Internet}

Berdasarkan hasil penelitian yang dilakukan, diketahui bahwa $13.25 \%$ memiliki keterbukaan dalam komunikasi interpersonal, sebagian besar dapat disimpulkan siswa $(86.75 \%)$ siswa tidak terbuka pada saat berkomunikasi melalui internet, sehingga komunikasi interpersonal tergolong tidak baik.

Menurut Devito (1997: 259-264) efektifitas komunikasi interpersonal adanya keterbukaan bahwa komunikator interpersonal yang efektif harus terbuka kepada orang yang diajaknya berinteraksi. Ini tidaklah berarti bahwa orang harus dengan segera membukakan semua riwayat hidupnya.memang ini mungkin menarik, tapi biasanya tidak membantu komunikasi. Sebaliknya, harus ada kesediaan untuk membuka diri mengungkapkan informasi yang biasanya disembunyikan, asalkan pengungkapan diri ini patut.

\section{Perhatian dalam Komunikasi Interpersonal melalui Internet}

Berdasarkan hasil penelitian yang dilakukan, diketahui bahwa $14.25 \%$ siswa yang memiliki perhatian dalam komunikasi interpersonal melalui internet, dapat disimpulkan sebagian besar siswa (85.75\%) tidak memiliki perhatian terhadap lawan komunikasinya, sehingga komunikasi interpersonal siswa tergolong tidak baik.

Komunikasi interpersonal menurut Bochner (dalam Devito, 2011: 252) devenisi berdasarkan komponen (componential) menjelaskan komunikasi antarpribadi dengan komponen-komponen utamanya-dalam hal ini, penyampaian pesan oleh satu orang dan penerimaan pesan oleh orang lain atau sekelompok kecil orang, dengan berbagai dampaknya dan dengan peluang untuk memberikan umpan balik segera.

\section{Empati dalam Komunikasi Interpersonal melalui Internet}

Berdasarkan hasil penelitian yang dilakukan, diketahui bahwa $21.44 \%$ siswa yang memiliki empati dalam komunikasi interpersonal melalui internet, dapat disimpulkan sebagian besar siswa (78.56\%) siswa kurang memiliki empati dalam komunikasi interpersonal, sehingga komunikasi interpersonal siswa melalui internet tergolong kurang baik.

Henry Backrack (dalam Devito, 1997: 160) mendefinisikan empati sebagai "kemampuan seseorang untuk 'mengetahui' apa yang sedang dialami orang lain pada suatu saat tertentu, dari sudut pandang orang lain itu, melalui kacamata orang lain itu."

Sejalan dengan hal itu Thill (2003:) komunikasi sebagai proses mengirim dan menerima pesan, dan bisa dikatakan efektif apabila pesan tersebut dapat dimengerti dan menstimuli tindakan atau mendorong orang lain untuk melakukan tindakan sesuai dengan pesan yang disampaikan tersebut.

\section{Kesetaraan dalam Komunikasi Interpersonal melalui Internet}

Berdasarkan hasil penelitian yang dilakukan, diketahui bahwa $19.65 \%$ siswa yang memperhatikan kesetaraan dalam komunikasi interpersonal melalui internet, sebagian besar siswa (80.35\%) kurang memperhatikan kesetaraan dalam komunikasi interpersonal sehingga dapat disimpulkan kesetaraan siswa dalam komunikasi interpersonal tergolong tidak baik.

Supratiknya (1995: 42) melalui tanggapan yang bersifat memberikan dukungan, penerima pesan ingin menunjukan sikap penuh simpati, meneguhkan kembali, atau menolong, meringankan beban pengirim pesan. Tanggapan sebaiknya tidak dilakukan dengan tergesa-gesa karena akan menyebabkan munculnya kesan meremehkan dan merendahkan bagi lawan bicara.

Menurut Devito (1997: 259-264) komunikasi interpersonal akan lebih efektif bila suasananya setara. Artinya, harus ada pengakuan secara diam-diam bahwa kedua pihak sama-sama bernilai dan berharga, dan bahwa masing-masing pihak mempunyai sesuatu yang penting untuk disumbangkan.

Jadi, dapat disimpulkan komunikasi interpersonal siswa pengguna internet secara keseluruhan belum baik, dalam berkomunikasi interpersonal melalui internet siswa harus memahami penggunaan internet yang baik, memahami tujuan penggunaan internet dengan baik, memiliki keterbukaan yang bertanggung jawab, perhatian terhadap lawan komunikasi, memiliki empati terhadap lawan komunikasi, dan adanya kesetaraan dalam berkomunikasi interpersonal melalui internet.

\section{Implikasi terhadap Layanan Bimbingan dan Konseling}

Menurut Prayitno (2012: 136) menjelaskan perkembangan konseling juga tidak lepas dari pengaruh perkembangan teknologi. Pada awalnya konseling hanya sebatas pertemuan tatap muka (face to face) antara 
konselor dan klien, namun saat ini konseling juga dapat diselenggarakan dengan berbagai media yang memungkinkan hubungan konseling jarak jauh.

Menurut Hafied Canggara (2008: 150) perkembangan teknologi komunikasi saat ini berpengaruh kepada perkembangan konseling yang awalnya tatap muka dapat dilakukan dengan perantaraan internet atau dikenal dengan istilah online. Hal ini dapat dijadikan sebagai salah satu cara untuk mengatasi permasalahan komunikasi yang ada pada siswa atau remaja yang merupakan salah satu pengguna internet terbesar saat ini.

Ron Kraus, dkk (dalam dalam Zadrian Ardi, Frischa Meivilona, 2012: 2) hal yang perlu diketahui konselor email dan chat program, email merupakan salah satu komunikasi standar pada internet, sedangkan text chat sedikit berbeda dari email sehingga pengguna (konselor dan klien) dapat berkomunikasi dengan keadaan real-time dengan menggunakan internet. Selanjutnya Ron Kraus, dkk mengemukakan videoconferencing merupakan suatu aplikasi yang hampir sama dengan text chat, namun selain mengandung unsur pertukaran informasi melalui text juga terjadi komunikasi melalui tampilan video masing-masing pengguna secara real-time.

Selain konseling online guru BK juga dapat memanfaatkan layanan-layanan konseling untuk membantu masalah komunikasi interpersonal siswa yang menjadi pengguna internet.

Berdasarkan permasalahan yang terungkap dari hasil penelitian materi layanan yang dapat diberikan sesuai dengan permasalahan komunikasi interpersonal siswa pengguna internet diantaranya komunikasi efektif, penggunaan internet yang baik, pembukaan diri dan sebagainya. Materi ini disesuaikan dengan layanan bimbingan dan konseling sesuai dengan pendapat ahli.

Prayitno, 2004 menjelaskan 9 layanan bimbingan dan konseling yakni layanan orientasi, layanan informasi, layanan penempatan dan penyaluran, layanan pengguasaan konten, layanan konseling perorangan, layanan bimbingan kelompok, layanan konseling kelompok, layanan konsultasi, dan layanan mediasi.

\section{PENUTUP}

Berdasarkan hasil analisis data yang telah dibahas maka dapat diambil kesimpulan sebagai berikut : (1) Hanya sebahagian siswa yang menggunakan internet untuk berinteraksi dengan pengguna lain, memberikan tanggapan, menyampaikan pesan, mencari informasi, dan menerima informasi, $\quad$ (2) Sebagian besar siswa tidak terbuka terhadap lawan komunikasi sehingga, keterbukaan dalam komunikasi interpersonal siswa melalui internet tergolong tidak baik, (4) Sebagian besar siswa tidak memberikan perhatian dalam komunikasi interpersonal, sehingga keterbukaan siswa dalam komunikasi interpersonal melalui internet tidak baik, (5) Sebagian besar siswa belum menerapkan kesetaraan dengan baik dalam komunikasi interpersonal, sehingga komunikasi interpersonal siswa internet tergolong kurang baik, (6) Implikasi terhadap layanan bimbingan dan konseling berupa peningkatan kemampuan berkomunikasi interpersonal oleh siswa pengguna internet itu sendiri dan pemberian bantuan berupa layanan bimbingan dan konseling dengan materi-materi yang berkaitan dengan masalah komunikasi interpersonal siswa serta pemanfaatan konseling online oleh guru BK

\section{DAFTAR PUSTAKA}

Alo, Liliweri. 1997. Komunikasi Antarpribadi. Bandung: Citra Aditya Bakti.

A. Muri, Yusuf. 1997. Metodologi Penelitian. Padang: UNP Press.

Anne, Ratnasari. 2005. Pengaruh Komunikasi Antarpribadi Bermedia Internet terhadap Persahabatan Mahasisa di dunia Maya. Mediator Vol. 8 No. 1Juni 2007. Dalam http://PB.pdf. Diakses pada tanggal 27 November 2012.

Astutik, Nur Qomariah. 2011. Perilaku Penggunaan Internet pada Kalangan Remaja Perkotaan. dalam www.primofpdf.com. Diakses pada tanggal 27 November 2012.

Devito A, Joseph. 1995. Komunikasi Antar Manusia. Jakarta: Profesional Book. 
Devito A, Joseph. 2011. Komunikasi Antar manusia. Edisi kelima. Tangerang: Karisma Pubishing Group. Editor Agus Maulana.

Dian, Wisnuwardhani \& Mashoedi F. Sri. 2012. Hubungan Interpersonal. Jakarta: Salemba Humanika.

Elvinaro, Ardianto \& Lukiati, Komala \& Siti, Karlinah. 2007. Komunikasi Massa. Bandung: Simbiosa Rekatama Media.

Hafied, Canggara. 2008. Pengantar Ilmu Komunikasi. Jakarta: Rajawali Pers.

Muhammad, Budyatna \& Leila ,Ganiem .M.. 2011. Teori Komunikasi Antar Pribadi. Jakarta : Kencana Prenada Media Group.

Sasa, Senjaya Djuarsa, dkk. 2007. Teori Komunikasi Edisi Dua. Jakarta:

Universitas Terbuka. 